\title{
Application of Principal Component Analysis (PCA) in a Nutritional Intervention Program Performed in Overweight and Obese Pediatric Patients
}

\section{Liliana Urbina-Jaramillo ${ }^{1}$, Valeria Cereceres-Rodríguez ${ }^{1}$, Eduardo Santellano-Estrada ${ }^{2}$, Paola María Núñez-Méndez ${ }^{1}$, Minerva Váldez-Arzate ${ }^{1}$ and Blanca G Beltrán ${ }^{1 *}$}

${ }^{1}$ Faculty of Nursing and Nutriology, Autonomous University of Chihuahua, Campus UACH II, Periférico de la Juventud, Chihuahua, México

${ }^{2}$ Faculty of Zootechnics and Ecology, Autonomous University of Chihuahua, Periférico Francisco, Chihuahua, México

*Corresponding Author: Blanca G Beltrán, Faculty of Nursing and Nutriology, Autonomous University of Chihuahua, Campus UACH II, Periférico de la Juventud, Chihuahua, México.
Received: November 09, 2021

Published: November 25, 2021

(C) All rights are reserved by Blanca G

Beltrán., et al.

\begin{abstract}
Introduction: Childhood obesity is a serious public health problem in Mexico. A nutritional intervention program (NIP) and the construction of nutritional status index for its prevention, can prevent non-communicable diseases in adulthood; and communicable ones such as COVID-19.

Objective: Apply a Principal Component Analysis (PCA) to evaluate the effect of a NIP in overweight and obese pediatric patients.

Methodology: 50 children between the ages of 7 and 13 years old participated. A clinical record and a nutritional diagnosis were prepared. A descriptive analysis was made using measures of central tendency, dispersion, and variable association; Pearson's correlations, Student's " $t$ " tests for paired samples, univariate analysis of variance (ANOVA), multivariate (MANOVA) and a Cluster analysis were performed to form groups of children with similar multivariate behavior. A nutritional index (NI) was obtained for the patients using a PCA.

Results: The NIP showed a statistically significant effect $(\mathrm{p} \leq 0.05)$ on anthropometric response variables. The weight mean decrease $9.7 \pm 0.3 \mathrm{Kg}$. The intestinal habit and age significantly affected $(\mathrm{p} \leq 0.01)$ the "Change in Weight" and the "Change in BMI" variable. The fast-food intake frequency and sweetened drinks decreased. Using the PCA, two components were selected that explained 94.9\% of the total nutritional variation observed in the patients.

Conclusion: At the end of the NIP, the multivariate behavior of pediatric patients changed positively and the dispersion of children in the variables involved decreased.
\end{abstract}

Keywords: Childhood Obesity; Principal-component-analysis; Eating-habits; Nutrition-intervention; COVID-19

\section{Introduction}

Obesity is a multifactorial chronic disease (genetic, metabolic, psychosocial, and environmental factors) that often begins in childhood or adolescence. Defined by an imbalance between daily energy intake and expenditure, characterized by excessive accumulation of fat, weight gain, and body volume [1-3]. 
Several studies have established that childhood obesity is a risk factor linked to higher cardiovascular disease, hypertension, hypercholesterolemia, and type II diabetes cases in adults $[4,5]$. Moreover, obesity is a risk factor that can aggravate COVID-19 symptoms in young patients. The first scientific evidence reported from the United States and Canada confirms that more than 20\% of $[6,7]$ young patients (6 years and older) admitted to pediatric intensive care units for COVID-19 had obesity [8]. Rivas-Ruiz., et al. (2020) report that children positive for SARS-CoV-2 in Mexico had a statistically higher obesity percentage [9].

The National Health and Nutrition Survey 2018-2019 in Mexico showed $8.1 \%$ and $17.5 \%$ of overweight and obesity prevalence (respectively) in children between 5 and 11 years old. Children and adolescents between 12 and 19 years old revealed $23.8 \%$ and $14.6 \%$ of overweight and obesity prevalence. In recent years, statistics indicate that a third of the population between 5 and 11 years old has excess body weight (overweight plus obesity), becoming a serious public health problem. In addition, Mexico is among the top 10 countries with the highest obesity prevalence in children of 5 to 19 years old. Thus, a big challenge poses in institutions responsible for Public Health and Child Welfare to help mitigate factors that affect the health and quality of life of the most vulnerable children [10-13].

In recent years, community strategies for nutritional surveillance and health promotion have been developed through the acquisition of healthy eating habits $[1,4]$. Nutritional intervention programs (NIPs) have been designed, organized, and implemented to gradually achieve the nutritional model fitting towards a healthier profile [12], to promote better nutrition education, and in turn, prevent noncommunicable diseases in adulthood [14]. Besides, contribute to decreasing obesity as a risk factor that aggravates diseases, such as COVID-19 [3,7].

Body mass index (BMI) is the most common tool used to diagnose obesity. However, the current concept and measurement analysis present inaccuracies and biases. Therefore, new assessment and screening alternatives should include a multifactorial analysis that involves more variables. Principal Component Analysis (PCA) is applied to explore the relationship between elements of a population to predict whether this relationship is somehow influenced by a set of variables or by the properties of the elements themselves [15].
However, current studies that use PCA for the analysis of nutritional intervention outcomes are scarce. Therefore, this research aimed to apply Principal Components Analysis to evaluate the effect of a Nutritional Intervention Program on pediatric patients with overweight and obesity who attend their medical appointments in a Health Center in Chihuahua, Mexico.

\section{Materials and Methods}

Method and study subjects

For this observational, descriptive, cross-sectional epidemiological study, 50 children aged between 7 and 13 years old, with obesity and overweight, participated.

Health Center authorities, parents, and/or legal guardians of the minors were previously informed about the research whereabouts. The Ethics and Research Committees of the Faculty of Nursing and Nutriology of the Autonomous University of Chihuahua, Mexico, issued a favorable opinion (official letter 115). Also, the Health Center Human Resources Department granted a permit to carry out the study, besides the parent's or guardians' informed consent to guarantee data protection and confidentiality. The study was carried out for six months, monitoring patients each month. With an approximate 20-30-minute consultation time.

On the first appointment, a clinical record was constructed, including personal information, pathological diseases, hereditary family history, 24-hour reminders, and frequency of fast-food intake. We investigated eating behavior (appetite, intake, swallowing) and bowel habit (normal, constipation, or diarrhea). An appointment schedule was delivered to participants, explaining the program's whereabouts to elaborate a nutritional diagnosis. Anthropometric measurements were made following the protocol established in the Data Collection Procedure Manual, specifically elaborated for the WHO (COSI) [16], International Society for the Advancement of Kinanthropometry (ISAK), technical recommendations [17], carried out by two previously trained nutritionists from the pediatrics area. During the measurements, the parents or guardians were always present with the minors.

Body weight was measured in kg using a digital scale (Healtho-meter model BFM 580-01, Shanghai, China), with a $0.1 \mathrm{~kg}$ sensitivity. Body height was measured in $\mathrm{cm}$, standing, using a portable

Citation: Blanca G Beltrán., et al. "Application of Principal Component Analysis (PCA) in a Nutritional Intervention Program Performed in Overweight and Obese Pediatric Patients". Acta Scientific Nutritional Health 5.12 (2021): 96-105. 
Application of Principal Component Analysis (PCA) in a Nutritional Intervention Program Performed in Overweight and Obese Pediatric Patients

stadimeter (Avanutri 312, Mexico). BMI was calculated using the following equation: weight $(\mathrm{Kg})$ divided by height squared (m2). Instruments were calibrated for every 25 weight and height measurements. We also provided a list of healthy snacks and examples for physical activation involving the whole family. At each appointment, we provide teaching material to parents or guardians regarding: "Basic food handling and preparation practice", besides adjusting the nutritional plan according to the patients' requirements. We use a similar procedure for the following four appointments.

Patients who improved their anthropometric measures: appetite habits, and fast-food intake, were dismissed, providing their nutritional diagnosis results and evolution during the study period. Patients who did not achieve the objectives were invited to resume the NIP.

\section{Statistical analysis}

- A descriptive analysis was performed using central tendency, dispersion, and association statistics between pairs of variables.

- Pearson correlations and Student's t-tests were estimated to compare variables means measured before and after the intervention.

- Univariate analysis of variance (ANOVA) was performed to test differences in changes by the effect of various classification factors (gender, age, appetite, initial conditions, habits, and intake).
- A Principal Component Analysis was applied to obtain a patient's nutritional status index and to observe changes in multidimensional variability.

- Cluster analysis was performed to obtain children's groups with similar multivariate behavior. And univariate Analysis of Variance (ANOVA) and multivariate Analysis of Variance (MANOVA) was run to test differences between the groups formed. Data were analyzed using Minitab version 17 and SAS version 9.0 statistical programs.

\section{Results}

The descriptive statistics results for the sample of 50 pediatric patients are shown in table 1 . BMI initially calculated showed a $98 \%$ obesity prevalence and $2 \%$ overweight prevalence at baseline (P95 to P99, obesity conditions). These results are consistent with percentile values found in CDC growth charts (Centers for Disease Control and Prevention) in children of the same age and gender, where the overweight is determined as a BMI between the 85th and 95th percentile; obesity is defined as a BMI in the 95th percentile or higher (18). At the end of the intervention, it was observed that children (boys and girls) are in lower percentiles P47 and P88 (healthy weight and overweight values).

The Ward linkage method was used to form four groups of children hierarchically and systematically. A stratification of groups of children (Appointment 1 and Appointment 5) was performed (Figure 1 and 2). Wilks' Lambda statistic showed a multivariate statistical difference between groups ( $\mathrm{p} \leq 0.0001)[19,20]$.

\begin{tabular}{|c|c|c|c|c|c|c|c|c|c|c|c|c|}
\hline \multirow{2}{*}{ Variables } & \multicolumn{6}{|c|}{ Girls before intervention } & \multicolumn{6}{|c|}{ Girls at the end of intervention } \\
\hline & Mean & aSD & ${ }^{\mathrm{b}} \mathrm{VC}$ & Mín. & Med. & Max. & Mean & SD & VC & Mín. & Med. & Max. \\
\hline Size $(\mathrm{m})$ & 1.4 & 0.1 & 7.8 & 1.2 & 1.4 & 1.6 & 1.4 & 0.1 & 7.8 & 1.2 & 1.5 & 1.6 \\
\hline Age (years) & 10.8 & 1.9 & 17.2 & 7 & 11 & 13 & 10.8 & 1.9 & 17.2 & 7 & 11 & 13 \\
\hline 'BMI & 25 & 2.5 & 9.8 & 19.2 & 25.4 & 29.6 & 20.2 & 2.1 & 10.6 & 16.5 & 21 & 23.5 \\
\hline Weight (kg) & 52.2 & 11.9 & 22.9 & 30 & 54 & 71 & 42.3 & 10.2 & 24.1 & 26 & 43 & 60 \\
\hline Waist circumference $(\mathrm{cm})$ & 78.6 & 6.9 & 8.8 & 65 & 81 & 89 & 68.4 & 6.3 & 9.2 & 57 & 70 & 79 \\
\hline \multirow[t]{2}{*}{ Variables } & \multicolumn{6}{|c|}{ Boys before intervention } & \multicolumn{6}{|c|}{ Boys at the end of intervention } \\
\hline & Mean & ${ }^{\mathrm{a} S D}$ & bVC & Mín. & Med. & Max. & Mean & $\mathrm{SD}$ & $\mathrm{VC}$ & Mín. & Med. & Max. \\
\hline Size $(\mathrm{m})$ & 1.4 & 0.1 & 9.8 & 1.3 & 1.5 & 1.7 & 1.5 & 0.2 & 10.5 & 1.2 & 1.5 & 1.7 \\
\hline Age (years) & 10.3 & 2.2 & 21 & 7 & 11 & 13 & 10.3 & 2.2 & 21 & 7 & 11 & 13 \\
\hline 'BMI & 24.8 & 2.2 & 8.8 & 20.7 & 25.4 & 30.3 & 19.8 & 2.4 & 11.9 & 15.4 & 20 & 24.7 \\
\hline Weight (kg) & 52.2 & 11.9 & 22.9 & 30 & 54 & 71 & 42.6 & 12.5 & 29.2 & 26 & 44 & 62 \\
\hline Waist circumference $(\mathrm{cm})$ & 80.6 & 9.2 & 11.5 & 65 & 80 & 95 & 71.2 & 9.3 & 13 & 52 & 72 & 87 \\
\hline
\end{tabular}

Table 1: Pediatric patients sample descriptive statistcs

${ }^{\mathrm{a}} \mathrm{SD}=$ Standard deviation; ${ }^{\mathrm{b}} \mathrm{VC}=$ Variation coefficient; ${ }^{\mathrm{C}} \mathrm{BMI}=$ Body Mass Index.

Fuente: Directa.

Citation: Blanca G Beltrán., et al. "Application of Principal Component Analysis (PCA) in a Nutritional Intervention Program Performed in Overweight and Obese Pediatric Patients". Acta Scientific Nutritional Health 5.12 (2021): 96-105. 


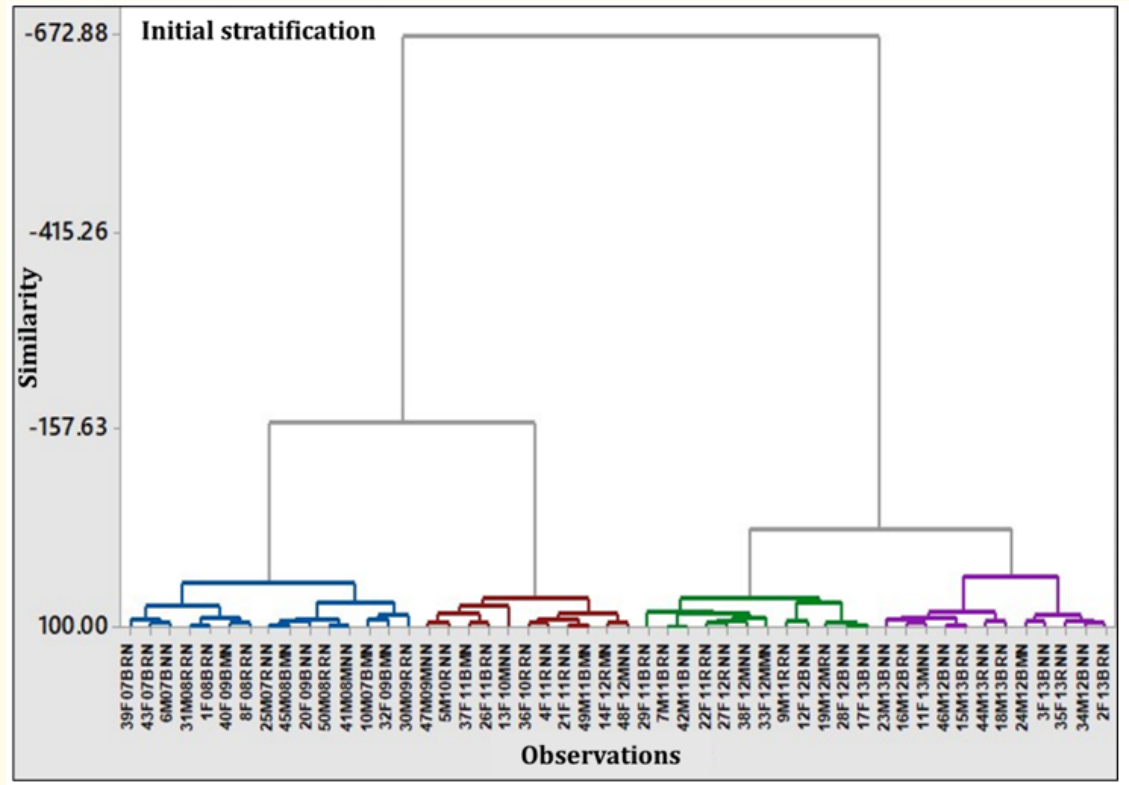

Figure 1: Grouping dendrograms of pediatric patients based on their multivariate similarity (Beginning of NIP). Source: Table 2.

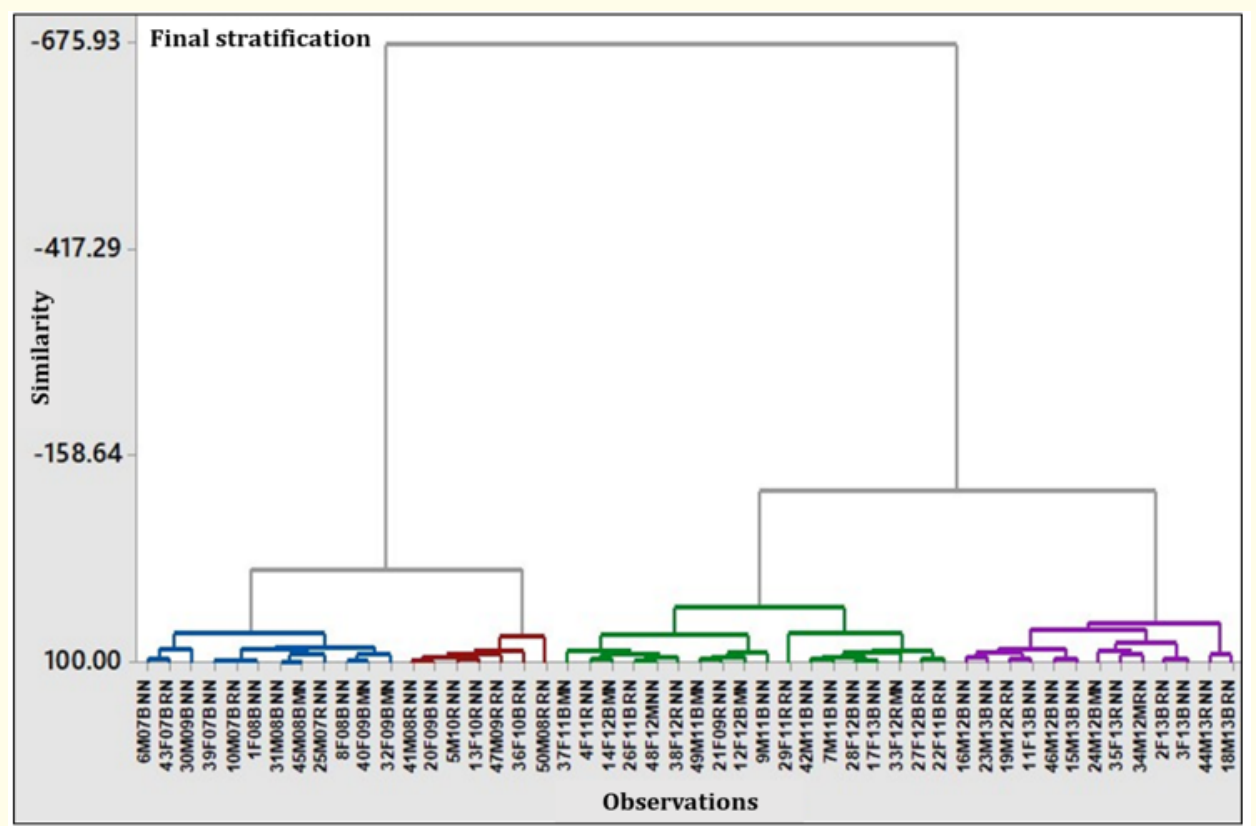

Figure 2: Grouping dendrograms of pediatric patients based on their multivariate similarity (End of NIP). Source: Table 2. 
Application of Principal Component Analysis (PCA) in a Nutritional Intervention Program Performed in Overweight and Obese Pediatric Patients

Initially, group 1 was composed of $53.3 \%$ boys and $46.3 \%$ girls. Like group 4, where boys were the majority (66.6\%). Group 2 consisted of $90 \%$ girls, and group 3,58.33\% girls. In terms of eating habits and behavior, group 1, 3, and 4 showed good appetite (53\%, $50 \%, 75 \%$ of boys and girls, respectively); only children of group 2 had regular appetite (45\%). Fast-food intake was normal at 56\%, $50 \%$, and $58 \%$ in groups 2,3 , and 4 . In group 1 , fast-food intake was regular (46.6\%). Swallowing resulted regular for all groups (100\%). The anthropometric variables in the four groups presented high values in weight, BMI, and waist circumference, placing the children in a condition of overweight and obesity (Table 2).

\begin{tabular}{|c|c|c|c|c|}
\hline \multirow{2}{*}{${ }^{a}$ Variables } & \multicolumn{4}{|c|}{ Groups at the beginning of NIP } \\
\hline & 1 (15) & $2(11)$ & $3(12)$ & $4(12)$ \\
\hline Size $(\mathrm{m})$ & $1.4 \pm 0.04$ & $1.4 \pm 0.5$ & $1.5 \pm 0.1$ & $1.6 \pm 0.04$ \\
\hline Age (years) & $7.9 \pm 0.8$ & $10.7 \pm 0.9$ & $11.7 \pm 0.7$ & $12.7 \pm 0.5$ \\
\hline 'BMI & $22.6 \pm 1.8$ & $24.7 \pm 1.2$ & $26.1 \pm 1.7$ & $26.9 \pm 1.5$ \\
\hline Weight (kg) & $37.3 \pm 3.6$ & $49.2 \pm 3.5$ & $59.8 \pm 2.7$ & $67.3 \pm 3.1$ \\
\hline $\begin{array}{l}\text { Waist cir- } \\
\text { cumference } \\
(\mathrm{cm})\end{array}$ & $69.8 \pm 3.5$ & $79.6 \pm 3.2$ & $82.5 \pm 4.01$ & $88.7 \pm 4.31$ \\
\hline \multirow[t]{2}{*}{ Variables } & \multicolumn{4}{|c|}{ Groups at the end of NIP } \\
\hline & $1(12)$ & $2(7)$ & $3(18)$ & $4(13)$ \\
\hline Size $(\mathrm{m})$ & $1.3 \pm 0.10$ & $1.4 \pm 0.1$ & $1.5 \pm 0.1$ & $1.6 \pm 0.04$ \\
\hline Age (years) & $7.8 \pm 0.8$ & $9.1 \pm 0.9$ & $11.5 \pm 0.6$ & $12.6 \pm 0.5$ \\
\hline${ }^{\mathrm{c} B M I}$ & $17.3 \pm 0.9$ & $18.3 \pm 1.1$ & $20.9 \pm 1.04$ & $22.3 \pm 1.2$ \\
\hline Weight (kg) & $28.2 \pm 2.3$ & $32.7 \pm 1.9$ & $46.1 \pm 3.6$ & $55.8 \pm 3.5$ \\
\hline $\begin{array}{l}\text { Waist cir- } \\
\text { cumference } \\
(\mathrm{cm})\end{array}$ & $59.5 \pm 3.4$ & $68.7 \pm 3.9$ & $70.7 \pm 4.04$ & $78.2 \pm 4.9$ \\
\hline
\end{tabular}

Table 2: Stratification based on children initial and final condition and progress regarding the NIP.

${ }^{\text {a }}$ Data reported as Means $(\mathfrak{R}) \pm$ Standard deviation. Direct source.

At the end of the intervention, groups 1, 2, and 4 consisted primarily of boys (58.3\%, 57\%, and $69.2 \%$, respectively). In group 1 , children registered good appetite (91\%); group 2 had regular appetite (71.4\%); groups 3 and 4 had a good appetite (61 - 69\% respectively). Values for regular fast-food intake exhibited similarity in the four groups $(58.3 \%, 57.14 \%, 50 \%, 61.5 \%$, groups 1,2 , 3 , and 4 , respectively). Thus, the characterization of each group shows lower values for the weight, BMI, and waist circumference variables (Table 2).
The correlation analysis between anthropometric variables shows a strong and significant ( $\mathrm{p} \leq 0.001$ ) direct (positive) linear association between all pairs of variables, with a Pearson correlation coefficient $(r)$ value close to 1 . In addition, after the NIP, the association that involved the variable "BMI" with other variables increased in all cases. A few variables showed a slightly lower correlation, i.e., between the variables: "waist circumference" and "age, height, and weight"; table 3 shows the correlation between the study variables for data obtained in Appointments 1 and 5 .

\begin{tabular}{|c|c|c|c|c|}
\hline Variables & $\begin{array}{c}\text { Age } \\
\text { (years) }\end{array}$ & $\begin{array}{l}\text { Size } \\
(\mathrm{m})\end{array}$ & $\begin{array}{l}\text { Weight } \\
\text { (Kg) }\end{array}$ & BMI \\
\hline \multirow[t]{2}{*}{$\operatorname{Size}_{(i)}$} & 0.915 & & & \\
\hline & $\leq 0.001$ & & & \\
\hline \multirow[t]{2}{*}{ Weight $_{(i)}$} & 0.938 & 0.952 & & \\
\hline & $\leq 0.001$ & $\leq 0.001$ & & \\
\hline \multirow[t]{2}{*}{$\mathrm{BMI}_{(\mathrm{i})}$} & 0.739 & 0.605 & 0.813 & \\
\hline & $\leq 0.001$ & $\leq 0.001$ & $\leq 0.001$ & \\
\hline \multirow{2}{*}{$\begin{array}{l}\text { Waist circumference } \\
(\mathrm{cm})_{(\mathrm{i})}\end{array}$} & 0.862 & 0.846 & 0.847 & 0.626 \\
\hline & $\leq 0.001$ & $\leq 0.001$ & $\leq 0.001$ & $\leq 0.001$ \\
\hline \multirow[t]{2}{*}{$\operatorname{Size}_{(f)}$} & 0.854 & & & \\
\hline & $\leq 0.001$ & & & \\
\hline \multirow[t]{2}{*}{ Weight $_{(f)}$} & 0.935 & 0.896 & & \\
\hline & $\leq 0.001$ & $\leq 0.001$ & & \\
\hline \multirow[t]{2}{*}{$\mathrm{BMI}_{(\mathrm{f})}$} & 0.881 & 0.742 & 0.923 & \\
\hline & $\leq 0.001$ & $\leq 0.001$ & $\leq 0.001$ & \\
\hline \multirow{2}{*}{$\begin{array}{l}\text { Waist circumference } \\
(\mathrm{cm})_{(\mathrm{f})}\end{array}$} & 0.759 & 0.674 & 0.785 & 0.704 \\
\hline & $\leq 0.001$ & $\leq 0.001$ & $\leq 0.001$ & $\leq 0.001$ \\
\hline
\end{tabular}

Table 3: Linear correlation coefficients between variables and pvalue associated to the beginning and the end of NIP.

${ }^{a} p$-value; ${ }^{(i)}$ Initial conditions; ${ }^{(f)}$ Final conditions.

Direct source.

The NIP effect on anthropometric response variables was proved, performing t-Student tests (paired or non-independent samples). The results presented (Table 4) indicate that for all the variables studied, we found a statistically significant effect $(\mathrm{p} \leq$ 0.05), except for the "size" variable, where the NIP effect was not significant. That may be due to short study time, which results in a lower size difference between the beginning and end of the intervention $(0.01 \mathrm{~m})$, contrary to the means difference recorded for the other variables. 


\begin{tabular}{|l|c|c|c|c|c|}
\hline $\begin{array}{l}\text { Final value vs } \\
\text { Initial value }\end{array}$ & $\begin{array}{c}\text { Teori- } \\
\text { cal t }\end{array}$ & $\begin{array}{c}\text { aReal } \\
\mathbf{t}\end{array}$ & p-value & ${ }^{\mathbf{b}} \mathfrak{R}_{\mathbf{f}}-\mathfrak{R}_{\mathbf{i}}$ & $\begin{array}{c}\text { cNIP } \\
\text { effect }\end{array}$ \\
\hline BMI $_{(\mathrm{f})}$ vs BMI $_{\mathrm{i}}$ & -28.19 & 2 & $\begin{array}{c}6.13 \mathrm{x} \\
10^{-32}\end{array}$ & 4.90 & + \\
\hline Size $_{(\mathrm{f})}$ vs Size $_{(\mathrm{i})}$ & 1.61 & 2.01 & 0.11 & 0.010 & - \\
\hline $\begin{array}{l}\text { Weight }_{(\mathrm{f})} \text { vs } \\
\text { Weight }_{(\mathrm{i})}\end{array}$ & -28.93 & 2.01 & $\begin{array}{c}1.8 \mathrm{x} \\
10-32\end{array}$ & 10.064 & + \\
\hline $\begin{array}{l}\text { Waist } \\
\text { circumference }_{(\mathrm{f})}\end{array}$ & -20.58 & 2.01 & $\begin{array}{c}9.15 \mathrm{x} \\
10^{-26}\end{array}$ & 9.85 & + \\
vs Waist $_{\text {circumference }}$ & & & & & \\
\hline
\end{tabular}

Table 4: t Student test for paired samples (non-independent) to evaluate the NIP effect

${ }^{a}$ t critical value (two tails); ${ }^{b}$ Mean difference $\left(\left(\Re_{\mathrm{f}}-\mathfrak{R}_{\mathrm{i}}\right) ;{ }^{\mathrm{c}}(+)\right.$ Effect;

$(-)$ No effect; (NIP) Nutritional Intervention Program; $\alpha=0.05$.

Direct source.

The NIP impact obtained was measured with an indicator called "change variable", which was calculated as the difference between the initial and final value for each variable measured in each child. ANOVA was used to determine whether various factors (gender, age, appetite, initial conditions, habits, and fast-food intake) had a significant effect on each changing variable. The "bowel habit (normal and constipation)" and "age" of pediatric patients significantly affected ( $\mathrm{p} \leq 0.011$ ) both the "change in weight" and "change in BMI" variables. While the "change in waist circumference" variable was not influenced by any of the study factors. Therefore, the NIP impact was the same for boys and girls, regardless of the overweight or obesity condition, or even the "Type of appetite (good, bad, and regular). It is relevant to point out that the ANOVA model included the initial values of the variables as co-variables or concomitant variables to make valid comparisons by eliminating the initial variation in the measured variables.

The PCA at the beginning of the intervention (Appointment 1) showed that the main component 1 (CP1) controlled $85.5 \%$ of the variability, and the main component 2 (CP2), 9.47\%. Both components explained $94.97 \%$ of the nutritional variation observed in 50 pediatric patients (Figure 3). All study variables were positively associated with CP1 by the correlation coefficient (r), with an equitable contribution in nutritional variance, which could perform as a general nutrition status index for patients. BMI and weight were negatively associated with CP2 (Table 5).

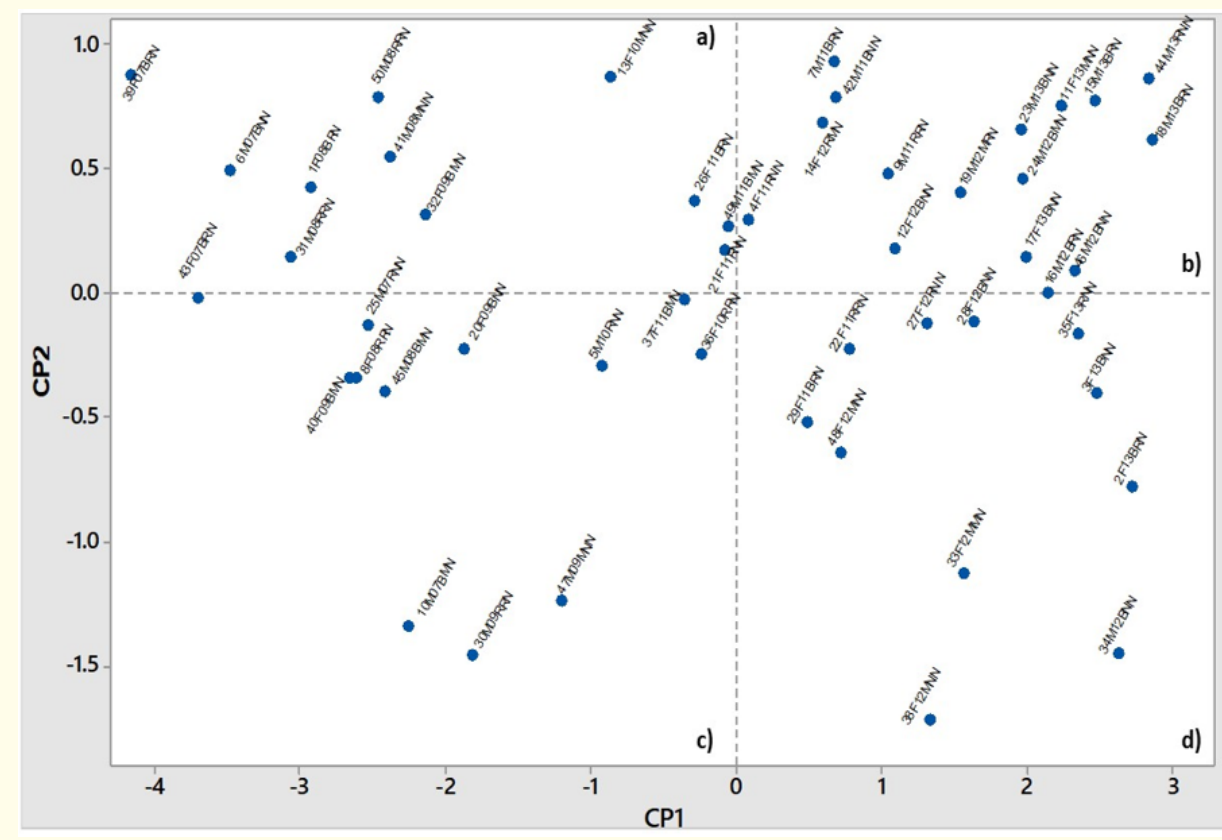

Figure 3: Distribution of the 50 pediatric patients at the beginning of NIP in two principal components (PC1 and PC2). Source: Principal Component Analysis. 


\begin{tabular}{|l|c|c|c|c|}
\hline \multicolumn{3}{|c|}{ Before NIP } & \multicolumn{2}{c|}{ After NIP } \\
\hline & PC1 & PC2 & PC1 & PC2 \\
\hline Own values & 4.275 & 0.459 & 4.2719 & 0.3536 \\
\hline Proportion & 0.855 & 0.092 & 0.854 & 0.071 \\
\hline Cumulative & 0.855 & 0.947 & 0.854 & 0.925 \\
\hline Variable & \multicolumn{5}{|c|}{ Correlation coefficient $\left(\mathrm{r}_{\mathrm{xy}}\right)$} \\
\hline Age & 0.468 & 0.091 & 0.465 & -0.139 \\
\hline Size & 0.455 & 0.382 & 0.437 & -0.368 \\
\hline Weight & 0.477 & -0.045 & 0.476 & -0.137 \\
\hline BMI & 0.392 & -0.860 & 0.446 & -0.165 \\
\hline Waist circumference & 0.439 & 0.324 & 0.408 & 0.894 \\
\hline
\end{tabular}

Table 5: Contribution of variables in the nutritional variance and correlation of variables, regarding the Principal Components.

Direct source.

After the intervention (Appointment 5), CP1 and CP2 explained $94.65 \%$ of nutritional variability. All study variables were positively associated with CP1 with an equitable contribution in nutritional variance. Thus, the same behavior and implications apply in the possible uses of CP1 as a general index for the children's nutri-

tional health status. Unlike the variables negatively associated with $\mathrm{CP} 2$, the waist circumference variable had the highest contribution $(89.4 \%)$ in the nutritional variation explanation (Table 5).

Figure 3 shows the wide distribution of pediatric patients in quadrants consisting of CP1 and CP2 (Appointment 1). In the quadrant "a", patients who presented the best nutritional status are located among age, weight, height, BMI, waist circumference, habits, and eating behavior variables. Quadrant "c" was like "a", with the exception that pediatric patients did not necessarily show the best values for the BMI variable. Quadrant "b" consisted of patients with values considered unsuitable for their nutritional status (i.e., high values in weight), but not necessarily in the BMI variable. Finally, quadrant " $d$ " consisted of patients who obtained high values in anthropometric variables, poor eating habits, and unwanted eating behavior. Initially, a reliable index for nutritional status was constructed with values between -4 to 3 (CP1) and -1.5 to 1 (CP2).

At the end of the intervention (Figure 4), pediatric patients' distribution showed a tendency to improve in a multivariate way, and children's general dispersion decreased due to the NIP effect. Nutritional index ranges varied from -4 to 4 for CP1 and -2 to 2 for CP2.

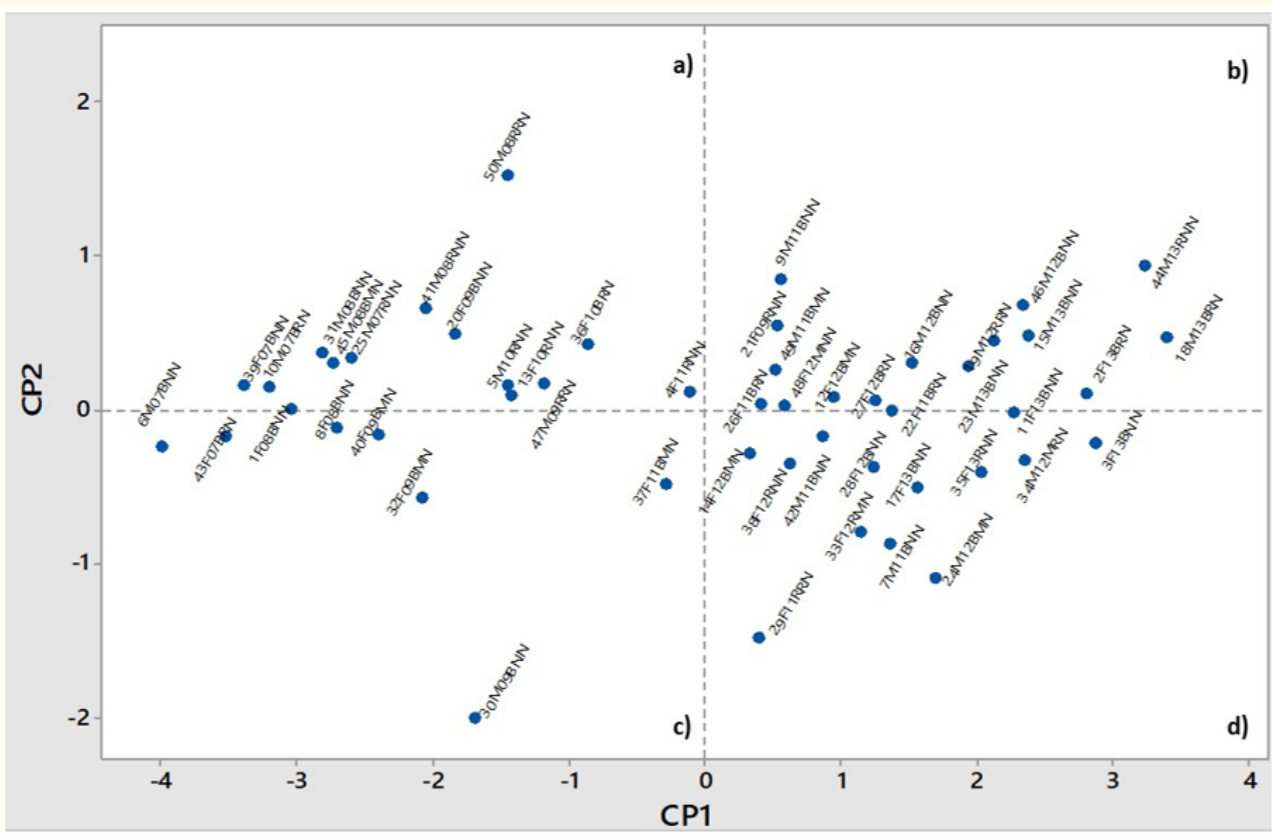

Figure 4: Distribution of the 50 pediatric patients at the beginning of NIP in two principal components (PC1 and PC2). Source: Principal Component Analysis. 
The fast-food intake frequency showed that $48 \%$ of children consumed fresh fruit, less than $24 \%$ fish, and chicken, and meat three times a week, less than $28 \%$ vegetables daily. All the children consumed fast food more than three times a week, and more than half drank soft drinks and sugary juices. Candies showed a 100\% of intake percentage. The NIP process generated positive changes, such as an increase in fruits (58\%) and vegetables (36\%) intake. Additionally, candy (64\%) and fast food (68\%) intake decreased. Dairy consumption remained constant throughout the whole NIP.

\section{Discussion}

The present study was conducted in 50 pediatric patients, within $10.8 \pm 1.8$ years old, with an obesity prevalence of $98 \%$ and $2 \%$ overweight prevalence at the beginning of the NIP.

Correlation analysis between the response variables involved showed a positive linear association between all variables. That is consistent with results obtained in a study conducted in Venezuela by Moya-Sifontes., et al. (2020), where they had a sample of children, adolescents, and university students $(n=655)$ and reported a positive correlation ( $r=0.71$ ) between the BMI, height, weight, waist circumference, and body fat variables (\%GC) [2].

Analysis of the NIP effect on anthropometric response variables showed a statistically significant change or effect ( $p \leq 0.05)$. Except for the variable "Size", where the effect was not significant due the study was conducted in a relatively short time (six months). Girls BMI decreased from $25 \pm 2.5$ to $20.2 \pm 2.1$; in boys, BMI went from $24.8 \pm 2.2$ to $19.8 \pm 2.4$, which represents a decrease of 4.8 and 5 points for girls and boys respectively. Other nutritional interventions reported similar values ( 4.4 - 4.5 points) in pediatric patients with similar program periods [21,22].

Initially, pediatric patients had an average weight of $52.2 \mathrm{Kg}$. After NIP, the weight recorded was $42.3 \pm 10.2 \mathrm{Kg}$ and $42.6 \pm 12$. $5 \mathrm{Kg}$, for boys and girls, respectively. With an average decrease of $9.7 \pm 0.3 \mathrm{Kg}$, for both genders, which represents an $18.58 \%$ weight loss. Other interventions achieved a weight decrease between 0.6 $10 \%[23,24]$.

The mean values for waist circumference were 78. $6 \pm 6.9 \mathrm{~cm}$ and $80.6 \pm 9.3 \mathrm{~cm}$ for girls and boys, respectively. However, by the end of the intervention, the waist circumference decreased to 68.4 \pm 6.3 in girls and $71.2 \pm 9.3$ in boys. The relevance of this achievement lies in the fact that waist circumference has a high correlation with abdominal fat (subcutaneous and visceral), total body fat, and is used as one of the best indicators of childhood obesity [25].

The NIP effect on categorical variables revealed that the number of cases of children with a "good" appetite increased from 27 to 34 , ensuring the absorption of nutrients necessary for their growth; "bad" appetite decreased from 8 to 2 [26]. The number of cases with "regular" appetite was 14 . The behavior for fast-food intake was as follows: initially, there were 9, 23, and 18 cases for slow, normal, and fast levels respectively. At the end of the NIP, it was possible to increase the number of cases with normal fastfood intake to 29. Likewise, fast-food intake decreased from 18 to 13 cases. Adequate fast-food intake promotes normal plasma concentrations of cholesterol, triglycerides, and lipoproteins [27]. Analysis of fast-food intake frequency showed that the intervention results were positive in this regard. Since, in boys and girls, the frequency of fast food and sweetening beverages intake decreased.

The PCA is a multivariate analysis methodology used to explain the variability source of a process and decrease data dimensionality. Achieved by transforming multidimensional information into lower variables that explain a large part of the fluctuations of the original variables, as well as their interrelations [15]. In this research, PCA was used as a statistical tool to explain patterns of nutritional status as a multivariate phenomenon. Two main components of obesity were obtained (CP1 and CP2), which summarized, represented $94.97 \%$ of the total nutritional variation observed in 50 pediatric patients. Initially, a reliable index for nutritional status was constructed with values between -4 to 3 (CP1) and -1.5 to 1 (CP2). At the end of the intervention, they range between -4 to 4 (CP1) and -2 to 2 (CP2). This nutritional status index (NI) allowed differentiation between well-nourished subjects and those that presented nutritional alteration, such as malnutrition, overweight, and obesity, through a multivariate analysis considering that the problems of obesity and overweight have multifactorial causes. Also, we could observe the positive advances achieved through nutritional intervention. With this methodology, it will be possible to establish the NI for each child who visits the Pediatrics Unit and take preventive actions if necessary to preserve their current and future health and well-being.

\section{Conclusion}

This research allowed us to evaluate the effect of a Nutritional Intervention Program in 50 pediatric patients with overweight and 
obesity in a pediatric unit in Mexico with solid statistical criteria. In addition, to a nutritional index (NI). The success obtained was due to the training, knowledge acquired, discipline, and commitment of the children and their parents. Promoting the acquisition of a healthier lifestyle and prevention of diseases in an adult stage. It is relevant to consider that obesity in children is a public health problem, not only in Mexico. But also, worldwide. In addition, the current COVID-19 pandemic situation in Mexico has caused high mortality in children [9]. Rivas-Ruiz., et al. (2020) reported that children in Mexico positive to SARS-CoV-2 had a statistically higher percentage of obesity.

\section{Acknowledgements}

The authors acknowledge the Autonomous University of Chihuahua in Mexico and the Civil Pension Care Unit, Chihuahua, Mexico, for their invaluable support in carrying out this Research Project.

\section{Conflict of Interest}

The authors declare no conflict of interest.

\section{Bibliography}

1. Browne Sarah., et al. "Effectiveness of interventions aimed at improving dietary behaviours among people at higher risk of or with chronic non-communicable diseases: an overview of systematic reviews". European Journal of Clinical Nutrition 73.1 (2018): 9-23.

2. Bauce Gerardo and Mary Zulay Moya-Sifontes. "Índice Peso Circunferencia de Cintura como indicador complementario de sobrepeso y obesidad en diferentes grupos de sujetos". Revista Digital de Postgrado 9.1 (2020).

3. Eyzaguirre Francisca., et al. "Prevalencia de síndrome metabólico en niños y adolescentes que consultan por obesidad". Revista Médica de Chile 39.6 (2011): 732-738.

4. Argelich Emma., et al. "Los equipos de pediatría ante la obesidad infantil: un estudio cualitativo dentro del proyecto STOP". Anales de Pediatría 95.3 (2021): 174-185.

5. Simmonds M., et al. "Predicting adult obesity from childhood obesity: a systematic review and meta-analysis". Obesity Reviews 17.2 (2015): 95-107.

6. Toro S., et al. "Plan Integral de Obesidad Infantil en Andalucia, SAS” (2021).

7. Cura Yayla Burcu Ceylan., et al. "Characteristics and Management of Children With COVID-19 in Turkey". Balkan Medical Journal 37.6 (2020): 341-347.
8. Shekerdemian, Lara S., et al. "Characteristics and Outcomes of Children With Coronavirus Disease 2019 (COVID-19) Infection Admitted to US and Canadian Pediatric Intensive Care Units". JAMA Pediatrics 174.9 (2020): 868.

9. Rivas-Ruiz, Rodolfo., et al. "Factores asociados a muerte en niños con COVID-19 en México". Gaceta de México 156.6 (2020).

10. Romero-Martínez Martín., et al. "Encuesta Nacional de Salud y Nutrición 2018-19: metodología y perspectivas”. Salud Pública de México 61.6 (2019): 917-923.

11. UNICEF. The state of the world's children 2019. Children, food and nutrition. Growing well in a changing world (2021).

12. UNICEF. "La pobreza, la urbanización, el cambio climático y las malas decisiones alimentarias dan como resultado dietas perjudiciales para la salud".

13. Merckx Joanna., et al. "Transmission of SARS-CoV-2 by children". Deutsches Aerzteblatt Online 117.33-34 (2020): 553-560

14. Aranceta-Bartrina J. "Nuevos retos de la nutrición comunitaria”. Revista Española de Nutrición Comunitaria 16.1 (2010): 51-55.

15. Härdle WK and Simar L. Applied Multivariate Statistical Analysis. Springer Berlin Heidelberg (2007).

16. Wijnhoven Trudy MA., et al. "WHO European Childhood Obesity Surveillance Initiative: Impact of Type of Clothing Worn during Anthropometric Measurements and Timing of the Survey on Weight and Body Mass Index Outcome Measures in 6-9-Year-Old Children". Epidemiology Research International (2016): 1-16.

17. Silva Vladimir Schuindt da and Maria Filomena Soares Vieira. "International Society for the Advancement of Kinanthropometry (ISAK) Global: international accreditation scheme of the competent anthropometrist". Revista Brasileira de Cineantropometria and Desempenho Humano 22 (2020): 22.

18. OMS. Intervenciones ELENA. Organización Mundial de la Salud (2021).

19. Ward Joe H. "Hierarchical Grouping to Optimize an Objective Function". Journal of the American Statistical Association 58.301 (1963): 236-244.

20. Schatzoff Martin. "Exact distributions of Wilks's likelihood ratio criterion”. Biometrika 53.3-4 (1966): 347-358. 
21. Partsalaki Ioanna., et al. "Metabolic impact of a ketogenic diet compared to a hypocaloric diet in obese children and adolescents". Journal of Pediatric Endocrinology and Metabolism 25.7-8 (2012): 697-704.

22. Siegel Robert M., et al. "An Office-Based Low-Carbohydrate Intervention in Teens". Clinical Pediatrics 50.11 (2010): 10621063.

23. Mohamad Hamdan., et al. "The Effect of Dietary and Exercise Interventions on Body Weight in Prostate Cancer Patients: A Systematic Review". Nutrition and Cancer 67.1 (2014): 43-60.

24. Marti T., et al. "Lasting effect of nutritional and exercise interventions on body weight: A comprehensive literature review". Public Health Nutrition 2.3 (2019): 186-196.

25. Finocchiaro Concetta., et al. "Effect of specific educational program on dietary change and weight loss in breast-cancer survivors". Clinical Nutrition 35.4 (2016): 864-870.

26. Flores-Olivares Luis Alberto., et al. "Circunferencia de cintura en cuatro sitios y su relación con indicadores de obesidad en escolares de 6 a 11 años". CienciaUAT 13.2 (2019): 18.

27. Carneiro FM., et al. "Efectos de la intervención nutricional sobre las variables antropométricas, la ingesta y las concentraciones de lípidos y lipoproteínas del plasma en niños con dislipidemia". Archivos Latinoamericanos de Nutrición 51.2 (2001): 132-144.

Volume 5 Issue 12 December 2021

(C) All rights are reserved by Blanca G Beltrán., et al. 